\title{
Assessment of UAV Based Vegetation Indices for Nitrogen Concentration Estimation in Spring Wheat
}

\author{
Olga S. Walsh ${ }^{*}$, Sanaz Shafian1, Juliet M. Marshall2 ${ }^{2}$, Chad Jackson' ${ }^{2}$, Jordan R. McClintick-Chess ${ }^{1}$, \\ Steven M. Blanscet ${ }^{3}$, Kristin Swoboda ${ }^{4}$, Craig Thompson ${ }^{4}$, Kelli M. Belmont ${ }^{5}$, Willow L. Walsh ${ }^{6}$ \\ ${ }^{1}$ Department of Plant Sciences, Southwest Research and Extension Center, University of Idaho, Moscow, ID, USA \\ ${ }^{2}$ Department of Entomology, Plant Pathology, and Nematology, Idaho Falls Research and Extension Center, University of Idaho, \\ Idaho Falls, ID, USA \\ ${ }^{3}$ BASF-Chemical Co., Caldwell, ID, USA \\ ${ }^{4}$ Take Flight UAS, LLC, Boise, ID, USA \\ ${ }^{5}$ Seminis, Payette, ID, USA \\ ${ }^{6}$ Vallivue High School, Caldwell, ID, USA \\ Email: *owalsh@uidaho.edu
}

How to cite this paper: Walsh, O.S., Shafian, S., Marshall, J.M., Jackson, C., McClintick-Chess, J.R., Blanscet, S.M., Swoboda, K., Thompson, C., Belmont, K.M. and Walsh, W.L. (2018) Assessment of UAV Based Vegetation Indices for Nitrogen Concentration Estimation in Spring Wheat. Advances in Remote Sensing, 7, 71-90

https://doi.org/10.4236/ars.2018.72006

Received: March 8, 2018

Accepted: May 15, 2018

Published: May 18, 2018

Copyright $\odot 2018$ by authors and Scientific Research Publishing Inc. This work is licensed under the Creative Commons Attribution International License (CC BY 4.0).

http://creativecommons.org/licenses/by/4.0/

(c) (i) Open Access

\begin{abstract}
Unmanned Aerial Vehicles (UAVs) have become increasingly popular in recent years for agricultural research. High spatial and temporal resolution images obtained with UAVs are ideal for many applications in agriculture. The objective of this study was to evaluate the performance of vegetation indices (VIs) derived from UAV images for quantification of plant nitrogen $(\mathrm{N})$ concentration of spring wheat, a major cereal crop worldwide. This study was conducted at three locations in Idaho, United States. A quadcopter UAV equipped with a red edge multispectral sensor was used to collect images during the 2016 growing season. Flight missions were successfully carried out at Feekes 5 and Feekes 10 growth stages of spring wheat. Plant samples were collected on the same days as UAV image data acquisition and were transferred to lab for $\mathrm{N}$ concentration analysis. Different VIs including Normalized Difference Vegetative Index (NDVI), Red Edge Normalized Difference Vegetation Index $\left(\mathrm{NDVI}_{\text {red edge }}\right)$, Enhanced Vegetation Index $2\left(\mathrm{EVI}_{2}\right)$, Red Edge Simple Ratio ( $\left.\mathrm{SR}_{\text {red edge }}\right)$, Green Chlorophyll Index $\left(\mathrm{CI}_{\text {green }}\right)$, Red Edge Chlorophyll Index $\left(\mathrm{CI}_{\text {red edge }}\right)$, Medium Resolution Imaging Spectrometer (MERIS) Terrestrial Chlorophyll Index (MTCI) and Red Edge Triangular Vegetation Index (core only) $\left(\mathrm{RTVI}_{\text {core }}\right.$ ) were calculated for each flight event. At Feekes 5 growth stage, red edge and green based VIs showed higher correlation with plant $\mathrm{N}$ concentration compare to the red based VIs. At Feekes 10 growth stage, all calculated VIs showed high correlation with plant $\mathrm{N}$ concentration.
\end{abstract}


Empirical relationships between VIs and plant $\mathrm{N}$ concentration were cross validated using test data sets for each growth stage. At Feekes 5, the plant $\mathrm{N}$ concentration estimated based on $\mathrm{NDVI}_{\text {red edge }}$ showed one to one correlation with measured $\mathrm{N}$ concentration. At Feekes 10, the estimated and measured $\mathrm{N}$ concentration were highly correlated for all empirical models, but the model based on $\mathrm{CI}_{\text {green }}$ was the only model that had a one to one correlation between estimated and measured plant $\mathrm{N}$ concentration. The observed high correlations between VIs derived from UAV and the plant $\mathrm{N}$ concentration suggests the significance of VIs deriving from UAVs for within-season $\mathrm{N}$ concentration monitoring of agricultural crops such as spring wheat.

\section{Keywords}

Unmanned Aerial Vehicles and Systems (UAV), Vegetation Indices (VIs), Plant Nitrogen Concentration

\section{Introduction}

Nitrogen $(\mathrm{N})$ is one of the essential factors for crop production in terms of plant growth and development and crop quality [1] [2]. Adequate supply of $\mathrm{N}$ is fundamental for optimizing wheat (Triticum aestivum L.) yield and grain quality [3] [4]. Nitrogen regulates plant growth processes and plays a vital role in chlorophyll (CL) production-the basis for the photosynthesis process [5]. Insufficient $\mathrm{N}$ supply can negatively affect photosynthesis process and result in crop yield and quality penalties [3]. On the other hand, excessive $\mathrm{N}$ application to agricultural crops has been associated with nitrate leaching, soil denitrification, ammonia volatilization, and nitrous oxide contamination of aquifers and aggravating the climate change [6] [7]. Dynamic and efficient fertilization (appropriate time and rate) is very important for optimizing crop yield and maintaining environmental quality [8]. Accurate estimation of crop $\mathrm{N}$ concentration is vital for developing effective fertilizer- $\mathrm{N}$ recommendations.

There is a strong correlation between $\mathrm{N}$ concentration and CL content at foliar and canopy scale because most of leaf $\mathrm{N}$ is localized within the CL molecules [9] [10] [11] [12]. Chlorophyll content is the main elements that govern the crop reflectance in the visible (VIS) and near infrared (NIR) regions of spectrum [8]. Thus, vegetation reflectance in these parts of spectrum is closely associated with $\mathrm{N}$ concentration. Remote sensing enables to acquire crop reflectance and provide diagnostic information on crop $\mathrm{N}$ concentration quickly and in a spatial context, compared to traditional destructive sampling techniques [13]. During the last few decades, scientists have proposed several vegetation indices (VIs) calculated from reflectance data to assess CL content and $\mathrm{N}$ concentration [8] [13] [14] [15]. These VIs are mostly a combination of NIR and VIS spectral bands, representing radiation scattering by canopy and radiation absorption by CL respectively [16]. Although these VIs accurately estimate CL and N concen- 
tration early in the growing season at lower CL values, they become less sensitive as the red spectral band is strongly absorbed by CL. Gitelson and Merzlyak [17] showed that red edge region is sensitive to a wide range of CL content values, and the use of this part of spectrum in VIs calculation can reduce the saturation effect due to lower absorption of the red edge region by CL. Several VIs based on this spectral region have been developed and used successfully to estimate CL and $\mathrm{N}$ concentration.

Gitelson and Merzlyak [17] replaced the red spectral band (675 nm) with red edge spectral band $(705 \mathrm{~nm})$ in Normalized Difference Vegetation Index (NDVI) and developed a new index called Red Edge Normalized Difference Vegetation Index $\left(\mathrm{NDVI}_{\text {red edge }}\right)$. They showed that traditional NDVI had a tendency to become saturated at higher CL level of senescing maple and chestnut leaves

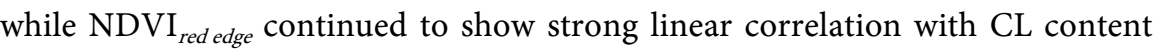
and observed no saturation issue. In a similar study, Gitelson et al. [18] showed that reciprocal of red edge spectral band is closely related to the CL content in leaves of all species. They proposed Red Edge Chlorophyll Index $\left(\mathrm{CI}_{\text {red edge }}\right)$ and showed that $\mathrm{CI}_{\text {red edge }}$ is highly correlated with CL content (coefficient of determination $\mathrm{R}^{2}>0.94$ ). In another study, Dash and Curran [19] developed MERIS Terrestrial Chlorophyll Index (MTCI). They used data in three red/NIR wavebands centered at $681.25,708.75$ and $753.75 \mathrm{~nm}$ (bands 8,9 and 10 in the MERIS standard band setting) to develop MTCI. They determined the relationship between MTCI and CL content using actual CL content for sites in the New Forest, United Kingdom (UK) and for small plots in a greenhouse experiment. Their results showed that MTCI is strongly and positively correlated to actual CL content. Li et al. [5] evaluated red edge based spectral indices for estimating plant $\mathrm{N}$ concentration and uptake of maize (Zea mays L.). They calculated chlorophyll content index (CCCI), NDVI red edge $\mathrm{CI}_{\text {red edge }}$ and MTCI from hyperspectral narrow bands, simulated Crop Circle ACS-470 active crop canopy sensor bands and simulated WorldView-2 satellite broad bands. Their results showed that there is a positive strong correlation between red edge based VIs and $\mathrm{N}$ concentration in maize. Their results also indicated that CCCI performed the best across different bandwidths for estimating maize plant $\mathrm{N}$ concentration at the V6 and V7 and V10 - V12 stages. In another study, Wang et al. [20] compared broad-band and red edge based spectral VIs to estimate $\mathrm{N}$ concentration in corn, wheat, rice (Oryza sativa L.) and soybeans (Glycine max L.). They calculated various VIs from images acquired by the Compact Airborne Spectrographic Imager (CASI) sensor. Their result showed that NDVI performed the best compared to other VIs, and red edge based VIs did not show potential for accurate estimation of leaf $\mathrm{N}$ concentration data due to spectral resolution.

Unmanned aerial vehicles (UAVs) are remote sensing systems that can capture crop reflectance in the VIS-NIR region of spectrum and assess CL and N concentration. The UAVs, which have recently gained tractions in number of studies, acquire ultra-high spatial resolution images by flying at low altitudes 
[21] [22]. Operational advantages such as low-cost systems, high flexibility in terms of flight planning and acquisition scheduling, and imaging below cloud cover make UAVs an appropriate tool to study crop biophysical parameters including $\mathrm{N}$ concentration [23]. In a few studies, scientists have used reflectance data derived from UAVs to estimate CL or N concentration. Lu et al. [24] mounted a Mini Multi-Camera Array (Mini-MCA) imaging system on an octocopter UAV to estimate rice $\mathrm{N}$ status. They examined various VIs to estimate $\mathrm{N}$ concentration at panicle initiation and stem elongation growth stages in rice. Their results showed that MTCI was best for estimating rice $\mathrm{N}$ concentration with $\mathrm{R}^{2}=0.48$. In another study, Caturegli et al. [25] compared the spectral reflectance of three turfgrasses (Cynodon dactylon $\times$ transvaalensis $(C d x t)$ "Patriot", Zoysia matrella $(\mathrm{Zm})$ "Zeon" and Paspalum vaginatum $\left(P_{V}\right)$ "Salam") acquired with a UAV and using a ground based instrument. They also tested the sensitivity of the two data acquisition sources in detecting induced variation among $\mathrm{N}$ application levels and for NDVI calculation. Their results showed that NDVI obtained with the ground based sensor was highly correlated with UAV based NDVI, with correlation coefficient values ranging from 0.83 to 0.97 . They also showed that UAV based NDVI was strongly correlated with $\mathrm{N}$ measured in the clipped plant biomass samples (correlation coefficient of 0.95). Similarly, Hunt et al. [26] used a UAV to monitor N status of irrigated potato (Solanum tuberosum L.). They used a small parafoil-wing UAV to acquire color-infrared images. They showed that each of applied $\mathrm{N}$ treatments could be precisely distinguished in the images. Their results also concluded that NDVI and Green Normalized Difference Vegetation Index (GNDVI) were not useful for in-season $\mathrm{N}$ management in potato because the above-ground changes in leaf CL were not sufficiently large to be detected by remote sensing early in the growing season.

So far, very few studies have investigated the potential of using red edge based VIs from the UAV data for canopy CL or N concentration estimation. To date, no studies on comparing red edge based VIs from the UAV data for wheat canopy CL or $\mathrm{N}$ concentration estimation have been reported. The main goal of this study was to evaluate the performance of UAV based VIs in estimating plant $\mathrm{N}$ concentration at canopy scale. Specifically, we analyzed and statistically compared the performance of different red edge based VIs from UAV data to estimate spring wheat plant $\mathrm{N}$ concentration.

\section{Materials and Methods}

\subsection{Study Area}

The experimental studies were conducted at five different locations in Idaho during 2016 growing season (Table 1 and Figure 1). The soil type, mean annual temperature, and mean annual precipitation for each study site are presented in Table 1.

Hard red spring wheat (cv. Cabernet) was planted using a Hege 500 series drill 
Table 1. Latitude, longitude, soil type, mean annual precipitation, and mean annual temperature for five locations in Idaho.).

\begin{tabular}{|c|c|c|c|c|c|}
\hline \multirow{2}{*}{ Field } & \multirow{2}{*}{ Lat } & \multirow{2}{*}{ Lon } & \multirow{2}{*}{ Soil Type } & \multicolumn{2}{|c|}{ Mean annual } \\
\hline & & & & precipitation & temperature \\
\hline Parma & 43.80243 & -116.94291 & Green leaf-Owyhee silt loams & $24 \mathrm{~cm}$ & $10^{\circ} \mathrm{C}$ \\
\hline Ashton & 44.07127 & -111.39983 & $\begin{array}{c}\text { Greentimber-Marystown-Robinlee } \\
\text { silt loams }\end{array}$ & $43 \mathrm{~cm}$ & $5^{\circ} \mathrm{C}$ \\
\hline Rupert & 42.72016 & -113.50641 & Sluka silt loam & $28 \mathrm{~cm}$ & $10^{\circ} \mathrm{C}$ \\
\hline
\end{tabular}

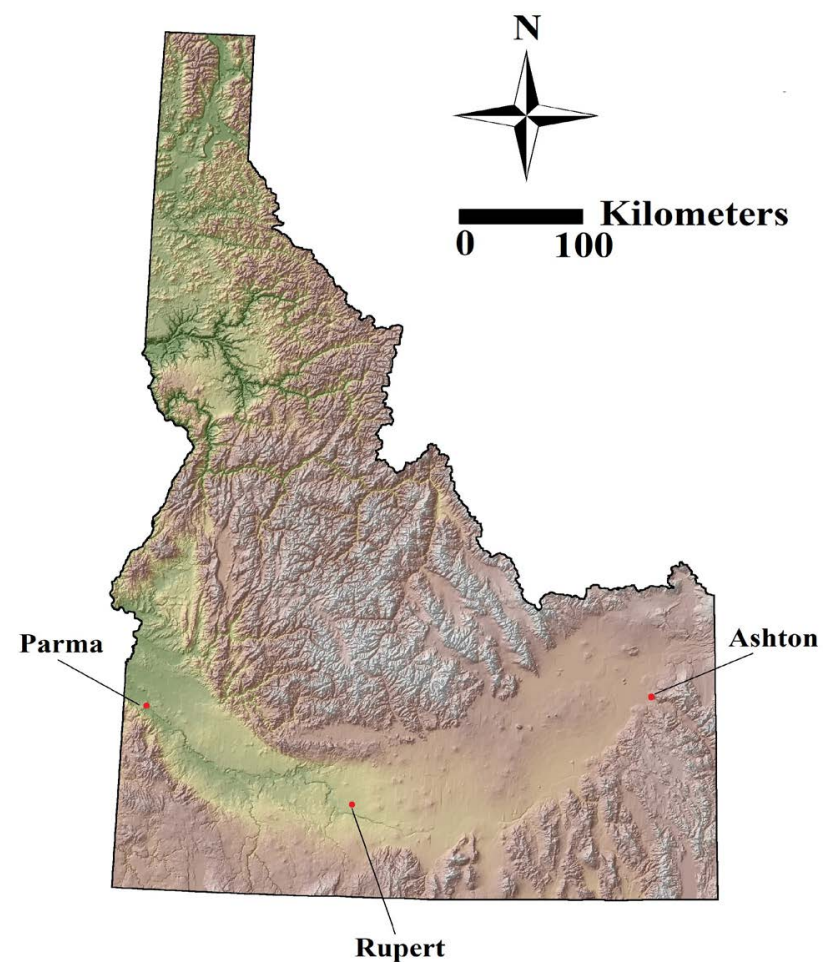

Figure 1. Example of a figure caption (figure caption).

at Rupert and Ashton, and soft white spring wheat (cv. Alturas) was planted at Parma using H\&N Equipment research plot drill, at a density of approximately $106.5 \mathrm{~kg}$ seeds ha ${ }^{-1}$. Row spacing was set at $17.78 \mathrm{~cm}$ using double disk openers. The plots were 1.52 wide by $4.27 \mathrm{~m}$ long, and then reduced to $3.05 \mathrm{~m}$ using glyphosate and tillage. Granular urea (46-0-0) was surface broadcasted immediately after planting at five different rates $\left(0,84,168,252\right.$, and $\left.336 \mathrm{~kg} \mathrm{~N} \mathrm{ha}^{-1}\right)$. Each treatment was replicated four times in a randomized complete block design, resulting in a total of 20 plots at each location. Spring planting conditions were good for crop establishment. Soil moisture March through April were above average, which resulted in excellent early season growth and development. Early season precipitation provided excellent growing conditions until irrigation became available in April when all sites were irrigated every 7 to 10 days using sprinkle irrigation systems. Timely planting dates resulted in excellent tillering and a long growing period. 


\subsection{Unmanned Aerial System}

A quadcopter UAV 3DR Solo (3D Robotics, Inc., Berkeley, CA) shown in Figure 2 was selected to carry camera payloads to acquire ultra-high-resolution imagery. Solo is powered by four electric brushless $880 \mathrm{kV}$ motors, two that spin clockwise, and two counterclockwise. Solo's arms are labeled 1 to 4 on the ends of the arms. Motors on arms \#1 and \#2 spin counterclockwise and use clockwise-tightening propellers with silver tops. Conversely, motors on arms \#3 and \#4 spin clockwise and use counter-clockwise tightening propellers with black tops. Solo's onboard computers control navigation, attitude, and communications in flight while sending real-time telemetry and video output and receiving control inputs over the 3DR Link secure WiFi network. A 14.8v dc $5200 \mathrm{mAh}$ lithium polymer ( $\mathrm{LiPo}$ ) rechargeable battery is located next to the power button. The intelligent battery systems on the Solo tracks battery power and informs the pilot when the battery needs to be recharged. Solo includes a GoPro ${ }^{\circledR}$ the Frame (GoPro, Inc, San Mateo, CA) fixed mount to support a GoPro ${ }^{\circledR}$ HERO camera (GoPro, Inc, San Mateo, CA). Alternatively, the fixed mount could be replaced by the optional 3-Axis Gimbal (3D Robotics, Inc, Berkeley, CA) (Figure 2). Empty weight of the quadcopter is $1.74 \mathrm{~kg}$ and weight increased to $1.9 \mathrm{~kg}$ with compatible camera and Solo Gimbal.

A MicaSense Red Edge ${ }^{\text {tw }} 3$ Multispectral Camera (MicaSense, Inc, Seattle, WA) with an integrated Global Positioning System (GPS) with an accuracy of 2 3 meters, mounted on the UAV was used to obtain the imagery. The camera was mounted on a Gimbal and as the camera's weight was similar to GoPro camera's weight, there was no need to add balance weight. The camera acquires 1.3-megapixel images in five spectral bands (red edge, near infrared, red, green, and blue) with 12-bit Digital Negative (DNG) or 16-bit Tag Image File Format (TIFF) radiometric resolution. The ground spatial resolution of resulting images from the narrowband imager is $8 \mathrm{~cm}$ (per band) at $120 \mathrm{~m}$ above ground level. The MicaSense Red Edge ${ }^{\mathrm{Tx}} 3$ has a Downwelling Light Sensor (DLS) (MicaSense,

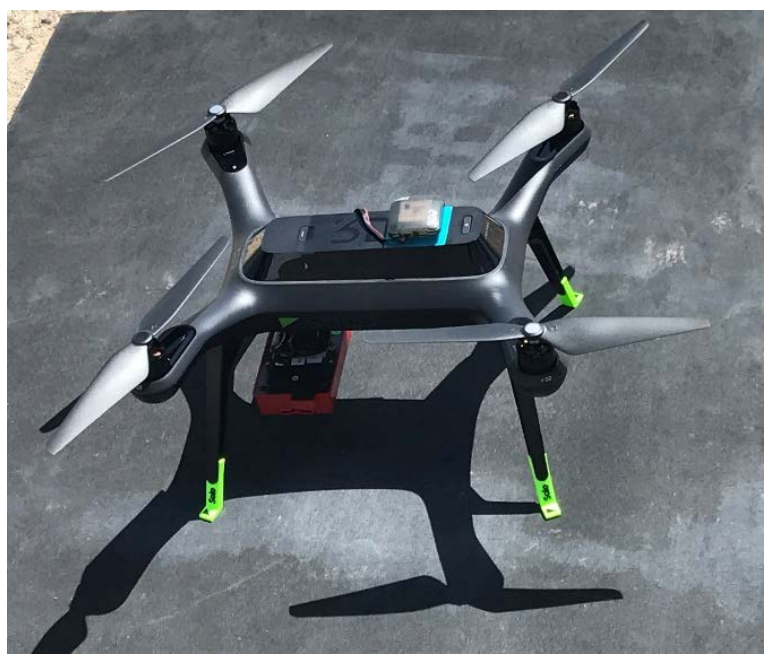

Figure 2. The Unmanned Aerial System 3DR Solo. 
Inc, Seattle, WA), which measures the ambient light during a flight for each of the five bands and records this information in the metadata of the images captured by the camera. The gain and exposure settings are automatically optimized for each capture and each band to prevent blurring or over-exposure, which results in properly exposed images.

\subsection{Multispectral Image Acquisition and Processing}

The UAV images were captured within 2.0 hours of solar noon with flight duration ranging from 15 to 20 minutes in sunny and cloud free conditions. Mission planer software [27] was used to design the flight path and choose the flight and sensor parameters to ensure there is an adequate overlap between acquired images for mosaicking. Two flight missions performed at each location to coincide with Feekes 5 and Feekes 10 spring wheat growth stages resulted in six flight missions per season. These growth stages were chosen because $\mathrm{N}$ fertilizer applied at these growth stages has potential to maximize grain yield and quality.

Acquired multispectral images were imported to Micasense Atlas software (MicaSense, Inc, Seattle, WA) for mosaicking, georeferencing and radiometric calibration. Micasense Atlas has a partnership with Pix4D mapper image analysis software (Pix4D SA, Lausanne, Switzerland) to create aligned, mosaicked and georeferenced images from multispectral data captured with the MicaSense red edge camera. The Pix4D finds hundreds of tie-points between overlapped images and stiches the individual images together to build one ortho-rectified image of the whole study area. The accuracy of an outputted reconstructed images are usually 1-2 times the ground spatial resolution. In this study, we had different treatments in the adjacent rows (100 cm row spacing) (well separated plots), so a low level of mosaicking error is allowable when using UAV images for our purpose [28]. Then, the mosaicked images were radiometrically calibrated using the Red Edge Camera Radiometric Calibration Model in Atlas software. Atlas software uses the calibration curve associated with a Calibrated Reflectance Panel (CRP) to perform calibration model and convert the raw pixel values of an image into absolute spectral radiance values. The CRP was placed adjacent to the study area during each flight mission, and an image of the CRP was captured immediately before and immediately after each flight. The output of radiometric calibration model is a 5-layer, 16-bit ortho-rectified GeoTIFF image.

\subsection{Field Sampling and Measurements}

To obtain a representative plant sample, aboveground biomass was destructively sampled at Feekes 5 and Feekes 10 growth stages by cutting three randomly selected plants in the middle of each plot immediately after each UAV flight event. Plant samples were dried in the oven for 72 hours at $80^{\circ} \mathrm{C}$ and then were transferred to the lab for $\mathrm{N}$ content analysis. Samples' $\mathrm{N}$ content analysis was performed using the AOAC method 990.3 [29] at Brookside Laboratories, Inc (New Bremen, OH, USA) with extended uncertainty of $\pm 5 \%$. 


\subsection{Vegetation Indices}

The UAV reflectance data were used for calculating eight VIs, many of which have been proposed as surrogates for canopy $\mathrm{N}$ concentration estimation. The VIs tested include the Normalized Difference Vegetation Index, NDVI [30], the Red Edge Normalized Difference Vegetation Index, NDVI ${ }_{\text {red edge }}$ [17], the Enhanced Vegetation Index 2, EVI2 [31], the Red Edge Simple Ratio, $\mathrm{SR}_{\text {red edge }}$ [32], the Green and Red Edge Chlorophyll Indices, $\mathrm{CI}_{\text {green }}$ and $\mathrm{CI}_{\text {red edge }}$, respectively [18], the MERIS Terrestrial Chlorophyll Index, MTCI [19], and the Core Red Edge Triangular Vegetation Index (RTVI ${ }_{\text {core }}$ ) [33] (Table 2). For each study plot, a region of interest (ROI) was manually established by choosing the central two rows and mean of each VI value corresponding to that plot was extracted.

\subsection{Statistical Analysis}

The study plots were randomly divided into test and training data sets. For the training data sets, simple regression analysis was performed to find the best relationship fit between $\mathrm{N}$ concentration and each UAV based VI. The determination coefficient $\left(\mathrm{R}^{2}\right)$ and Root Mean Squared Error (RMSE) were used to evaluate the predictive accuracy of each model. These parameters are widely used to evaluate the performance of empirical models. The RMSE are computed as shown in Equations (1):

$$
R M S E=\sqrt{\left[\frac{\sum_{i=1}^{M}\left(\hat{y}_{i}-y_{i}\right)^{2}}{M}\right]}
$$

where, $\hat{y}_{i}$ is predicted value of $N$ concentration; $y_{i}$ is measured $N$ concentration, and $M$ is total number of observations. In the next step, the test data set was used to evaluate the performance of developed model in the previous step. Predicted values of $N$ concentration were plotted versus corresponding values of $N$ concentration measured in the lab. The performance of regression models in estimating $N$ for the training data set were evaluated by calculating the $\mathrm{R}^{2}$ and

Table 2. Vegetation indices (VIs) tested in this study to estimate nitrogen (N) content.

\begin{tabular}{|c|c|}
\hline Vegetation Index & Equation \\
\hline Normalized Difference Vegetation Index (NDVI) & $(\mathrm{NIR}-\mathrm{Red}) /(\mathrm{NIR}+\mathrm{Red})$ \\
\hline $\begin{array}{l}\text { Red Edge Normalized Difference Vegetation Index } \\
\qquad\left(\mathrm{NDVI}_{\text {red edge }}\right)\end{array}$ & $(\mathrm{NIR}$ - Red Edge $) /(\mathrm{NIR}+$ Red Edge $)$ \\
\hline Enhanced Vegetation Index $2\left(\mathrm{EVI}_{2}\right)$ & $2.5 \times(\mathrm{NIR}-\mathrm{Red}) /(\mathrm{NIR}+2.4 \times \operatorname{Red}+1)$ \\
\hline Red Edge Simple Ratio $\left(\mathrm{SR}_{\text {red edge }}\right)$ & (NIR)/ (Red Edge) \\
\hline Green Chlorophyll Index $\left(\mathrm{CI}_{\text {green }}\right)$ & $(\mathrm{NIR} / \mathrm{Green})-1$ \\
\hline Red Edge Chlorophyll Index $\left(\mathrm{CI}_{\text {red edge }}\right)$ & $(\mathrm{NIR} / \mathrm{Red}$ Edge $)-1$ \\
\hline $\begin{array}{c}\text { Medium Resolution Imaging Spectrometer (MERIS) } \\
\text { Terrestrial Chlorophyll Index (MTCI) }\end{array}$ & $(\mathrm{NIR}-$ Red Edge $) /($ Red Edge + Red $)$ \\
\hline Core Red Edge Triangular Vegetation Index (RTVI $\left.{ }_{\text {core }}\right)$ & $100($ NIR - Red Edge $)-10($ NIR - Green $)$ \\
\hline
\end{tabular}


RMSE. In addition, Student's t-tests were used to determine if the slope and the intercept of the regressions were significantly different from 1 and 0 , respectively. If the values of slopes were not significantly different from 1 and the values of intercepts were not significantly different from 0 , then it was concluded that the regression was not significantly different from the 1:1 line, and the empirical model could accurately predict $\mathrm{N}$ concentration.

\section{Results and Discussions}

\subsection{Variation of Plant N Concentration}

Based on different $\mathrm{N}$ application rates, a wide range of $\mathrm{N}$ concentration (\%) ranged from $0.76 \%$ to $1.58 \%$ were obtained at Feekes 5 (Table 3 ). In Parma and Rupert sites, the highest $\mathrm{N}$ concentration (\%) were obtained at fertilizer $\mathrm{N}$ rate of $336 \mathrm{~kg} \mathrm{~N} \mathrm{ha}{ }^{-1}$ while in Ashton site, the highest $\mathrm{N}$ concentration (\%) was obtained at fertilizer $\mathrm{N}$ rate of $252 \mathrm{~kg} \mathrm{~N} \mathrm{ha}^{-1}$. Similarly, at Feekes 10 a wide range of $\mathrm{N}$ concentration (\%) ranged from $0.33 \%$ to $0.70 \%$ were obtained. In all sites, the highest $\mathrm{N}$ concentration (\%) were obtained at fertilizer $\mathrm{N}$ rate of $336 \mathrm{~kg} \mathrm{~N}^{-1}$. Generally, observed variations in $\mathrm{N}$ concentration were due to differences in climate, inherent soil fertility, and $\mathrm{N}$ rate applications. When comparing $\mathrm{N}$ fertilizer rate applications, in Parma and Rupert sites at both Feekes 5 and Feekes 10 growth stages, the rate of $\mathrm{N}$ fertilizer significantly affected $\mathrm{N}$ concentration. In Ashton site at Feekes 5, the rate of $\mathrm{N}$ fertilizer did not make significant changes in $\mathrm{N}$ concentration while at Feekes 10 , the rate of $\mathrm{N}$ fertilizer made significant changes in $\mathrm{N}$ concentration.

Across growth stages, applied $\mathrm{N}$ rates and locations, plant $\mathrm{N}$ concentration decreased at all locations (Table 3 and Table 4). These results indicate the "dilution effect" as the crop matured, as described in previous studies [34] [35]. Plant $\mathrm{N}$ concentration was lower for Ashton site at both Feekes 5 and Feekes 10 growth stages, compared to other sites. As all study sites were irrigated and had similar soil type (silt loam), the differences between plant $\mathrm{N}$ concentration for the same $\mathrm{N}$ application rates may be associated with differences in the amount of plant available water. Ashton site received $15 \mathrm{~cm}$ more precipitation compared

Table 3. Plant $\mathrm{N}$ concentration at Feekes 5, as affected by the applied $\mathrm{N}$ fertilizer rate

\begin{tabular}{cccc}
\hline \multirow{2}{*}{$\mathrm{N}$ rate $\left(\mathrm{kg} \mathrm{N} \mathrm{ha}^{-1}\right)$} & \multicolumn{3}{c}{ Mean Plant N Concentration (\%) } \\
\cline { 2 - 4 } & Parma & Ashton & Rupert \\
\hline 0 & $0.76 \mathrm{~d}$ & $0.76 \mathrm{a}$ & $1.31 . \mathrm{b}$ \\
84 & $1.05 \mathrm{c}$ & $0.80 \mathrm{a}$ & $1.41 \mathrm{~b}$ \\
168 & $1.18 \mathrm{~b}$ & $0.79 \mathrm{a}$ & $1.44 \mathrm{ab}$ \\
252 & $1.17 \mathrm{~b}$ & $0.83 \mathrm{a}$ & $1.39 \mathrm{~b}$ \\
336 & $1.32 \mathrm{a}$ & $0.82 \mathrm{a}$ & $1.58 \mathrm{a}$ \\
\hline
\end{tabular}

Means within each column followed by the same letter are not significantly different at $\mathrm{p}<0.01$, as determined by the Duncan's multiple range test. 
Table 4. Plant $\mathrm{N}$ concentration at Feekes 10, as affected by the applied $\mathrm{N}$ fertilizer rate.

\begin{tabular}{cccc}
\hline \multirow{2}{*}{ N rate $\left(\mathrm{kg} \mathrm{N} \mathrm{ha}^{-1}\right)$} & \multicolumn{3}{c}{ Mean Plant N Concentration (\%) } \\
\cline { 2 - 4 } & Parma & Ashton & Rupert \\
\hline 0 & $0.33 \mathrm{c}$ & $0.35 \mathrm{~b}$ & $0.33 \mathrm{c}$ \\
84 & $0.41 \mathrm{bc}$ & $0.39 \mathrm{ab}$ & $0.41 \mathrm{bc}$ \\
168 & $0.65 \mathrm{a}$ & $0.45 \mathrm{a}$ & $0.65 \mathrm{a}$ \\
252 & $0.49 \mathrm{~b}$ & $0.35 \mathrm{~b}$ & $0.49 \mathrm{~b}$ \\
336 & $0.70 \mathrm{a}$ & $0.45 \mathrm{a}$ & $0.70 \mathrm{a}$ \\
\hline
\end{tabular}

Means within each column followed by the same letter are not significantly different at $p<0.01$, as determined by the Duncan's multiple range test.

to Rupert, and $17 \mathrm{~cm}$ more than Parma. The similar result was obtained for the semiarid grassland by $\mathrm{Lu}$ [36]. In that study, Lu showed that water additions significantly interacted to affect plant $\mathrm{N}$ uptake and $\mathrm{N}$ concentrations at the community level.

\subsection{Plant N Concentration Models Development and Validation}

We used the training data set for establishing separate plant $\mathrm{N}$ content predictive models using UAV based VIs for Feekes 5 and Feekes 10 separately. The training data set includes a wide range of plant $\mathrm{N}$ content values due to differences in $\mathrm{N}$ application rates. Eight models were developed using the vegetation indices NDVI, NDVI ${ }_{\text {red edge, }}$ EVI2, $\mathrm{SR}_{\text {red edge }}, \mathrm{MTCI}, \mathrm{CI}_{\text {green }}, \mathrm{CI}_{\text {red edge }}$ and $\mathrm{RTVI}_{\text {core }}$. Figure 3 and Figure 4 show the best relationship fit between $\mathrm{N}$ concentration and each UAV based VI for Feekes 5 and Feekes 10, respectively. At Feekes 5 (Figure 3), the $\mathrm{R}^{2}$ of these models ranged from 0.69 to 0.88 and RMSE ranged from 0.096 to 0.16 . At this growth stage, the highest $\mathrm{R}^{2}$ between VIs and $\mathrm{N}$ concentrations was obtained for the $\mathrm{CI}_{\text {green }}$. Also, the developed model based on this index showed the lowest RMSE with $\mathrm{N}$ concentration. The best relationship fit between $\mathrm{N}$ concentration and most VIs at Feekes 5 were quadratic (Figure 3). $\mathrm{CI}_{\text {green }}$ and MTCI were the only VIs which their best relationship fit with $\mathrm{N}$ concentration were linear. At Feekes 10 (Figure 4), the $\mathrm{R}^{2}$ of the developed models ranged from 0.82 to 0.88 and RMSE ranged from 0.06 to 0.08 . At this growth stage, the largest $\mathrm{R}^{2}$ between VIs and $\mathrm{N}$ concentrations again was obtained for $\mathrm{CI}_{\text {green }}$ while the developed model based on NDVI $\mathrm{I}_{\text {red edge }}$ had the lowest RMSE with $\mathrm{N}$ concentration. The best relationship fit between $\mathrm{N}$ concentration and all VIs (except $\mathrm{EVI}_{2}$ ) at Feekes 10 were quadratic (Figure 4). EVI ${ }_{2}$ was the only VIs for which its' best relationship fit with $\mathrm{N}$ concentration was linear.

All UAV based VIs used in this study showed strong positive correlations with $\mathrm{N}$ concentration. In other words, all UAV based VIs used in this study were good indicators of spring wheat plant $\mathrm{N}$ concentration for both Feekes 5 and Feekes 10 growth stages. At Feekes 5 (Figure 3), red radiation based UAV indices (NDVI and EVI2) had lower $\mathrm{R}^{2}$ and higher RMSE as compared with other green and red edge based UAV indices. At this stage (lower fractional vegetation 

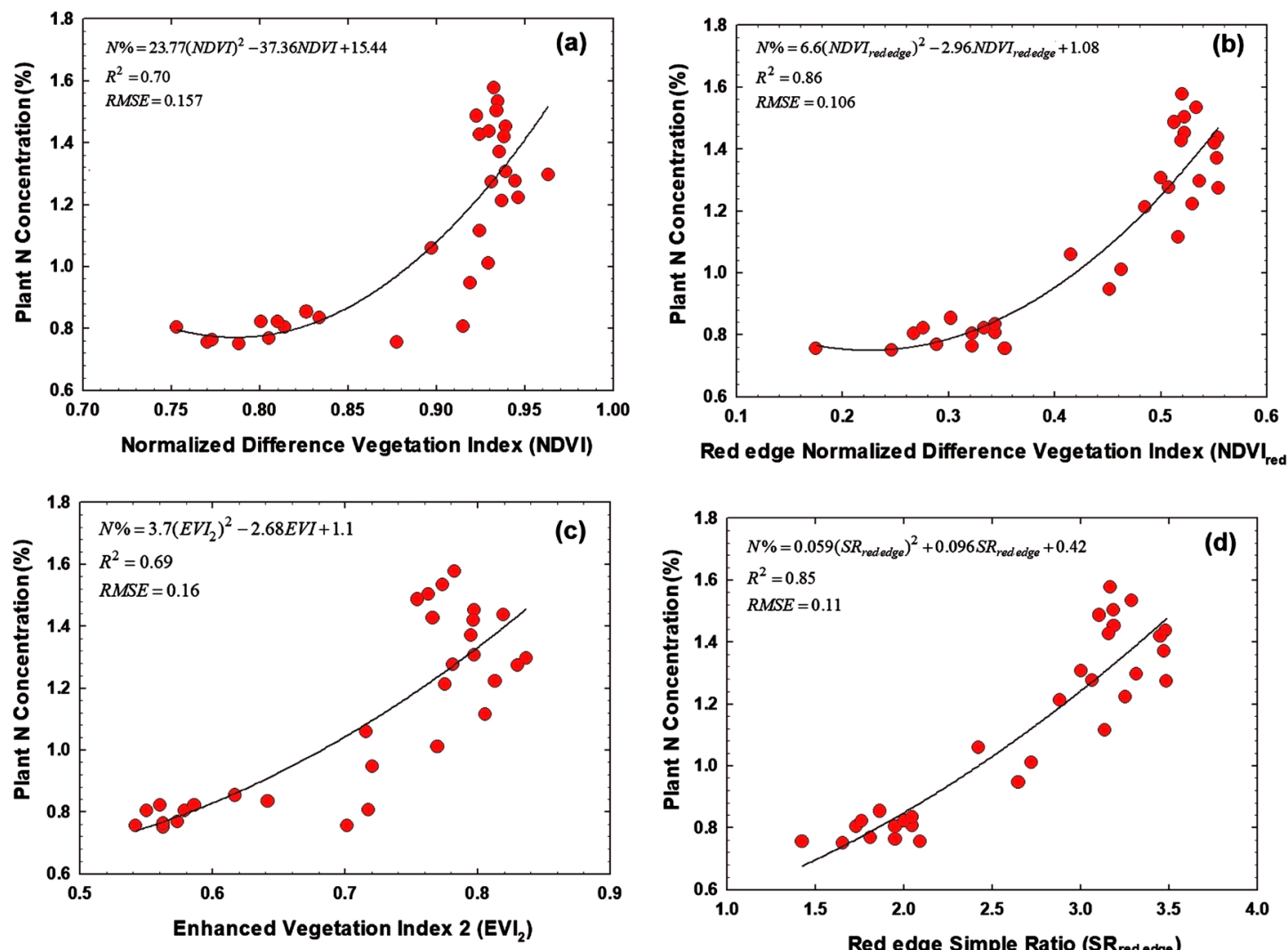

Red edge Normalized Difference Vegetation Index (NDVIred edge)
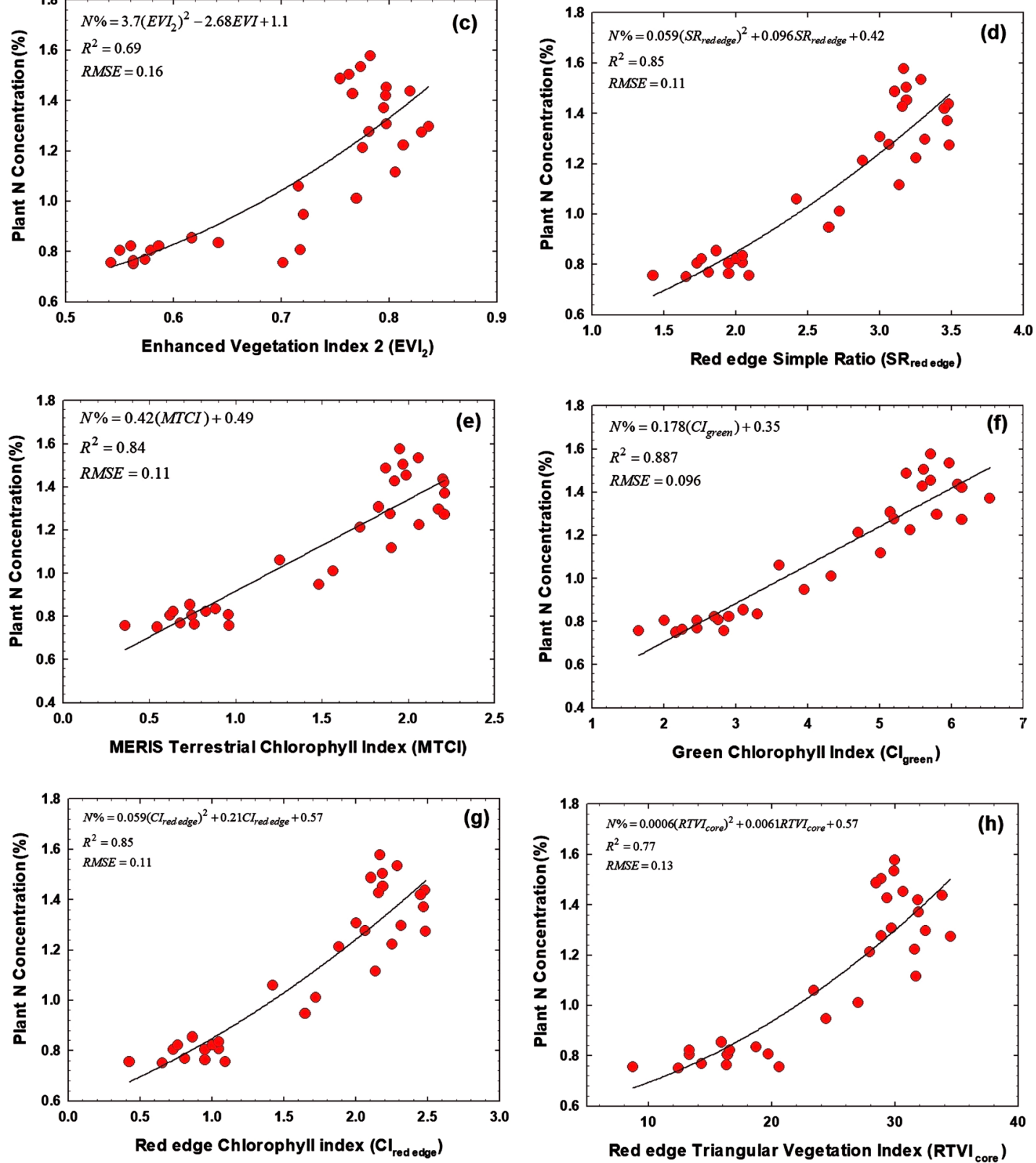

Figure 3. Relationships between measured plant N content (\%) vs. (a) NDVI, (b) NDVI $\mathrm{red}_{\text {edge }}$, (c) $\mathrm{EVI}_{2}$, (d) $\mathrm{SR}_{\text {red edge }}$, (e) MTCI, (f) $\mathrm{CI}_{\text {green }},(\mathrm{g}) \mathrm{CI}_{\text {red edge }}$ and (h) $\mathrm{RTVI}_{\text {core }}$ at Feekes 5 growth stage. 

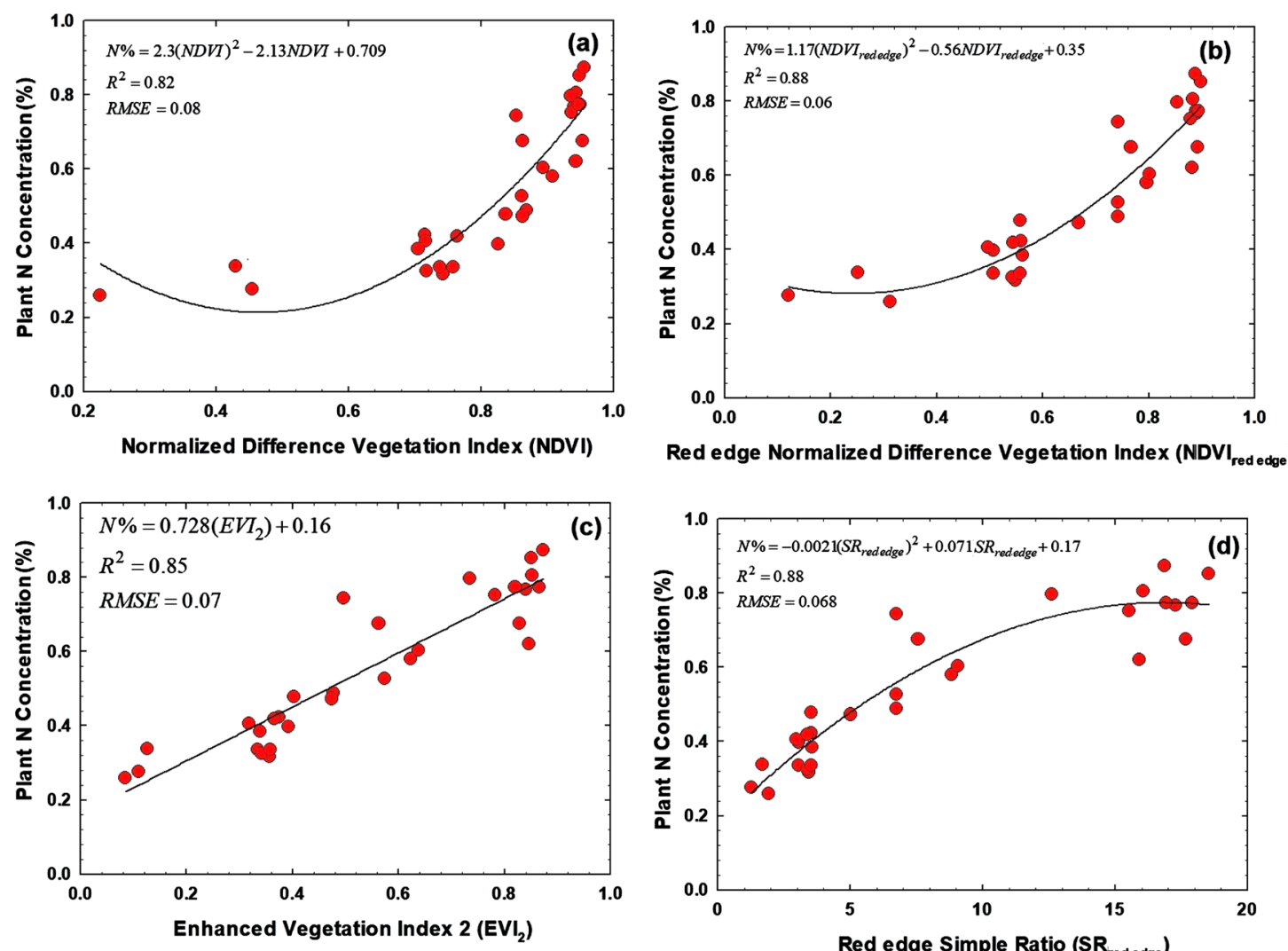

Red edge Normalized Difference Vegetation Index (NDVI ${ }_{\text {red edge }}$ )
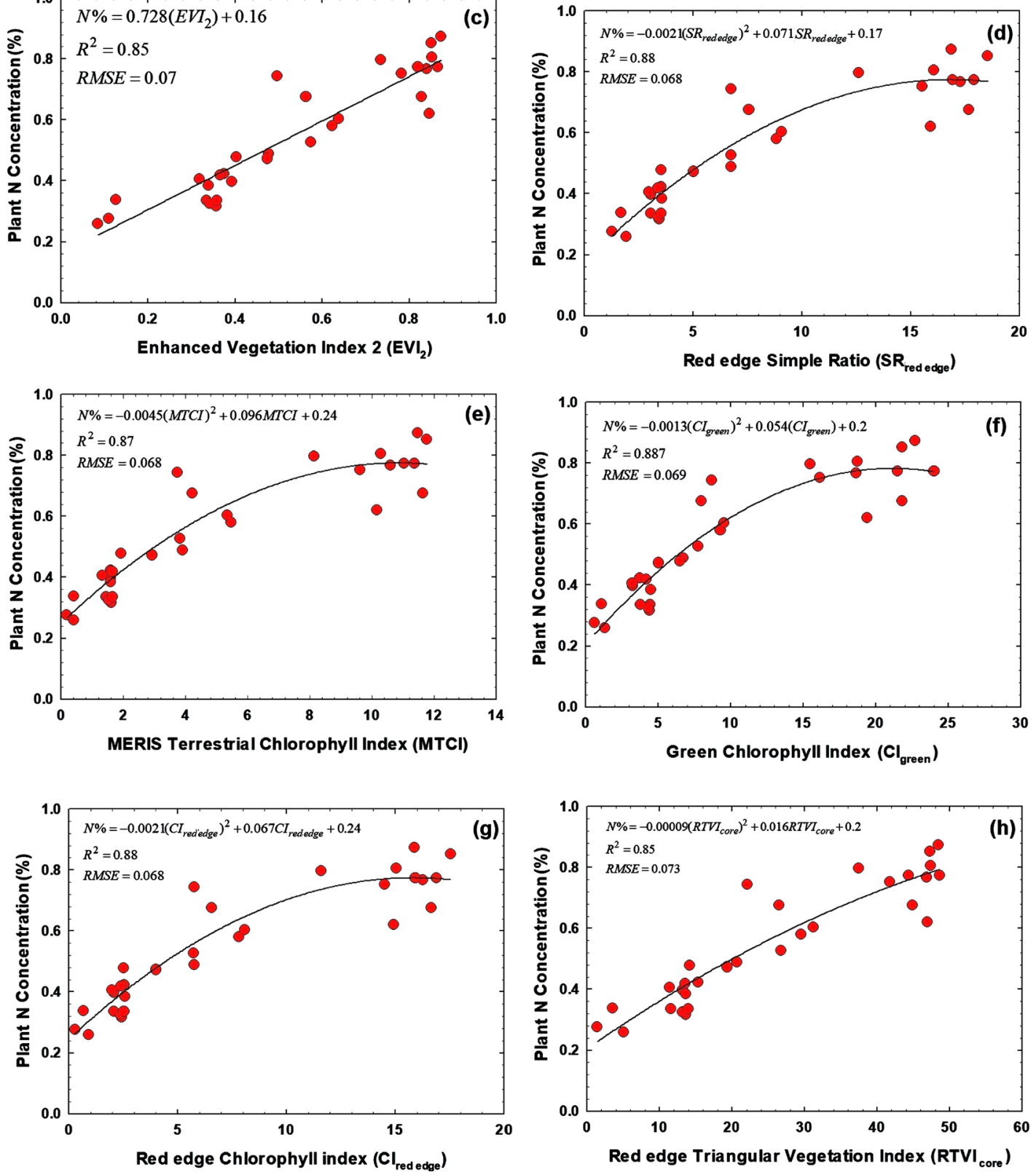

Figure 4. Relationships between measured plant N content (\%) vs. (a) NDVI, (b) NDVI red edge, (c) $\mathrm{EVI}_{2}$, (d) SRred edge, (e) MTCI, (f) $\mathrm{CI}_{\text {green }}$ ( $(\mathrm{g}) \mathrm{CI}_{\text {red edge }}$ and (h) $\mathrm{RTVI}_{\text {core }}$ at Feekes 10 growth stage. 
cover), soil background influence on research plots' reflectance could be strong and could negatively affect the red based VIs accuracy [37]. Red edge based VIs could minimize the soil reflectance and isolate crop signal from soil reflectance as a function of canopy cover changes [13]. This suggests that applying red edge based or green based VIs from UAVs data can improve plant $\mathrm{N}$ concentration prediction compared to the red based UAV VIs at Feekes 5 of wheat growth stage. At this stage, $\mathrm{CI}_{\text {green }}$ showed the highest $\mathrm{R}^{2}$ and lowest RMSE which suggests that the green based VIs can be a better indicator of plant $\mathrm{N}$ concentration than the red edge based VIs. This result is in consistent with the result of the previous study conducted by $\mathrm{Li}$ [38] who showed that red edge based VIs were more effective for $\mathrm{N}$ estimation at earlier growth stage of wheat. In addition, CIgreen showed linear relationship with plant $\mathrm{N}$ concentration, which means sensitivity of the model did not change due to the wide range of variation in plant $\mathrm{N}$ concentration; it is straightforward to invert them between $\mathrm{CI}_{\text {green }}$ and plant $\mathrm{N}$ concentration to obtain a synoptic measure of $\mathrm{N}$ concentration. All the red edge based VIs showed comparable performance with similar $\mathrm{R}^{2}$ and RMSE values at Feekes 5. At Feekes 10 growth stage (Figure 4), all UAV based VIs used in the study performed very well with similar $\mathrm{R}^{2}$ and RMSE values. At this stage, the performance of NDVI and EVI2 for plant N concentration improved. All other UAV based VIs had similar performance compare to Feekes 5. Similar results have been reported by previous studies as well [38]. At Feekes 10, the crop canopy had fully developed, and soil background effect on research plots' reflectance had been reduced, so red based and red edge based VIs showed similar performance.

The performance of the developed models in the previous step were evaluated using test data set for Feekes 5 and Feekes 10, separately. For this purpose, we used the developed models in previous step to estimate the $\mathrm{N}$ concentration. Table 5 and Table 6 show the results of comparison between measured $\mathrm{N}$ concentration and predicted $\mathrm{N}$ concentration retrieved from developed model in previous step for Feeks 5 and Feekes 10, respectively. At Feekes 5 (Table 5), the $\mathrm{R}^{2}$ of the relationship between measured and predicted $\mathrm{N}$ concentration ranged from 0.67 to 0.84 and RMSE ranged from 0.147 to 0.196 . At this growth stage, the lowest RMSE between measured and predicted $\mathrm{N}$ concentrations were obtained using the developed models based on RTVI $I_{\text {core }}$ and NDVI ${ }_{\text {red edge }}$ (Table 5). At this growth stage, all the developed models performed similar in terms of $\mathrm{R}^{2}$ (Table 5). The results of a Student's $t$ test showed that for the developed models based on $\mathrm{NDVI}_{\text {red edge, }} \mathrm{SR}_{\text {red edge }}$ and $\mathrm{CI}_{\text {red edge }}$ the slopes of those regression lines were not significantly different from $1(t=0.0279 ; t=0.43947 ; t=0.43706$ respectively) (Table 7), while a similar test showed that the intercepts of those lines were not significantly different from $0(t=1.026 ; t=0.730 ; t=0.731$, respectively) (Table 7). Thus, one could conclude that these regression lines were not significantly different from the 1:1 line. These results indicated that the developed model based on $\mathrm{NDVI}_{\text {red edge }}$ can predict the plant $\mathrm{N}$ concentration at Feekes 5 with best accuracy compared to other developed models (Figure 4(a)). 
Table 5. The results of algorithm cross validation for estimating plant $\mathrm{N}$ concentration $(\mathrm{N} \%)$ at Feekes 5 growth stage. Best fit functions, determination coefficients $\left(\mathrm{R}^{2}\right)$ and root mean square errors (RMSE) of plant $\mathrm{N}$ concentra-tion estimation are given for eight vegetation indices.

\begin{tabular}{cccc}
\hline VIs & Estimated $\mathrm{N} \%=\mathrm{a}($ measured N\%) $+\mathrm{b}$ & $\mathrm{R}^{2}$ & RMSE (\%) \\
\hline $\mathrm{NDVI}$ & $0.7265 \mathrm{x}+0.3464$ & 0.67 & 0.168 \\
$\mathrm{NDVI}_{\text {red edge }}$ & $1.026 \mathrm{x}+0.0815$ & 0.84 & 0.148 \\
$\mathrm{EVI}_{2}$ & $0.8167 \mathrm{x}+0.2694$ & 0.78 & 0.165 \\
$\mathrm{SR}_{\text {red edge }}$ & $1.0419 \mathrm{x}+0.0799$ & 0.84 & 0.179 \\
$\mathrm{CI}_{\text {green }}$ & $1.2495 \mathrm{x}-0.1527$ & 0.84 & 0.196 \\
$\mathrm{CI}_{\text {red edge }}$ & $1.0417 \mathrm{x}+0.08$ & 0.84 & 0.179 \\
$\mathrm{MTCI}$ & $0.7932 \mathrm{x}+0.3497$ & 0.84 & 0.160 \\
$\mathrm{RTVI}_{\text {core }}$ & $0.8434 \mathrm{x}+0.2811$ & 0.84 & 0.147 \\
\hline
\end{tabular}

Table 6. The results of algorithm cross validation for estimating plant $\mathrm{N}$ concentration (N\%) at Feekes 10 growth stage. Best fit functions, determination coefficients $\left(\mathrm{R}^{2}\right)$ and root mean square errors (RMSE) of plant $\mathrm{N}$ concentration estimation are given for eight vegetation indices.

\begin{tabular}{cccc}
\hline VIs & Estimated $\mathrm{N} \%=\mathrm{a}($ measured $\mathrm{N} \%)+\mathrm{b}$ & $\mathrm{R}^{2}$ & RMSE $(\%)$ \\
\hline $\mathrm{NDVI}$ & $0.728 \mathrm{x}+0.1509$ & 0.72 & 0.10 \\
$\mathrm{NDVI}_{\text {red edge }}$ & $0.769+0.143$ & 0.74 & 0.091 \\
$\mathrm{EVI}_{2}$ & $0.7778 \mathrm{x}+0.107$ & 0.73 & 0.095 \\
$\mathrm{SR}_{\text {red edge }}$ & $0.756 \mathrm{x}+0.147$ & 0.75 & 0.091 \\
$\mathrm{CI}_{\text {green }}$ & $0.891 \mathrm{x}+0.03$ & 0.76 & 0.090 \\
$\mathrm{CI}_{\text {red edge }}$ & $0.752 \mathrm{x}+0.141$ & 0.75 & 0.091 \\
$\mathrm{MTCI}$ & $0.785 \mathrm{x}+0.121$ & 0.75 & 0.090 \\
$\mathrm{RTVI}_{\text {core }}$ & $0.778 \mathrm{x}+0.163$ & 0.72 & 0.104 \\
\hline
\end{tabular}

Table 7. Regressions' analysis parameter, $t$ value, to determine if the slope and the intercept of the regressions were significantly different from 1 and 0 , respectively at Feekes 5.

\begin{tabular}{ccccccccc}
\hline VIs & NDVI & NDVI $_{\text {red edge }}$ & $\mathrm{EVI}_{2}$ & $\mathrm{SR}_{\text {red edge }}$ & $\mathrm{CI}_{\text {green }}$ & $\mathrm{CI}_{\text {red edge }}$ & MTCI & RTVI $_{\text {core }}$ \\
\hline Slop & -2.53856 & 0.0279 & -2.2772 & 0.43947 & 2.1633 & 0.43706 & -1.9776 & -1.7958 \\
Intercept & 2.8066 & 1.026 & 2.7678 & 0.730 & -1.1557 & 0.730 & 2.9279 & 2.8123
\end{tabular}

All $\mathrm{t}$ values were determined at $46 \mathrm{df}$ and $\alpha=0.05$.

Similarly, at Feekes 10, the $\mathrm{R}^{2}$ of the relationship between measured and predicted $\mathrm{N}$ concentration ranged from 0.72 to 0.73 and RMSE ranged from 0.09 to 0.104. At this growth stage, the lowest RMSE between measured and predicted $\mathrm{N}$ concentrations were obtained using the developed models based on $\mathrm{CI}_{\text {green }}$ and MTCI (Table 6). At this stage, all developed models had weaker performance in term of $\mathrm{R}^{2}$, but all models had smaller RMSE compared to Feekes 5. The results of a Student's t test showed that only for the model developed based on $\mathrm{CI}_{\text {green }}$, 
the slope of the regression line was not significantly different from $1(t=$ $-1.15722,46 \mathrm{df}, \alpha=0.05)$ (Table 8), while a similar test showed that the intercept of that line was not significantly different from $0(\mathrm{t}=0.6554,46 \mathrm{df}, \alpha=0.05)$ (Table 8). Thus, one could conclude this regression line was not significantly different from the 1:1 line. These results indicate that the model developed based on $\mathrm{CI}_{\text {green }}$ can predict the plant $\mathrm{N}$ concentration at Feekes 10 with greatest accuracy compared to other models, and can be successfully used to estimate plant $\mathrm{N}$ concentration of wheat crop in the future (Figure 4(b)).

In cross-validation process, results showed that at Feekes 5 developed model based on $\mathrm{NDVI}_{\text {red edge }}$ can predict the plant $\mathrm{N}$ concentration with best accuracy compared to other developed models. The developed model based on NDVI edge slightly underestimated the plant $\mathrm{N}$ concentration at lower values while overestimated the plant $\mathrm{N}$ concentration at higher values (Figure 5(a)). One possible reason for this is the soil type that was slightly different for each study site; it is possible that the total canopy reflectance was affected by slightly different background reflectance values at each location [39]. At Feekes 10, the developed model based on $\mathrm{CI}_{\text {green }}$ predicted the plant $\mathrm{N}$ concentration with highest accuracy compared to other models. The developed model based on $\mathrm{CI}_{\text {green }}$ at this growth stage did not have over- or underestimation issue as the crop canopy had been fully developed, which minimized the effect of different background reflectance soil values (Figure 5(b)).

At different growth stages, UAV based VIs showed different behaviors for

Table 8. Regressions' analysis parameter, $t$ value, to determine if the slope and the intercept of the regressions were significantly different from 1 and 0 , respectively at Feekes 5.

\begin{tabular}{lllllllll}
\hline VIs & NDVI & NDVI $_{\text {red edge }}$ & $\mathrm{EVI}_{2}$ & $\mathrm{SR}_{\text {red edge }}$ & $\mathrm{CI}_{\text {green }}$ & $\mathrm{CI}_{\text {red edge }}$ & $\mathrm{MTCI}$ & $\mathrm{RTVI}_{\text {core }}$ \\
Slop & -2.9701 & -2.9269 & -2.7852 & -3.2624 & -1.1572 & -2.876 & -2.6159 & -2.4721 \\
Intercept & 2.8194 & 3.1016 & 2.2996 & 3.3815 & 0.6554 & 2.809 & 2.5192 & 3.1225 \\
\hline
\end{tabular}

All t values were determined at $46 \mathrm{df}$ and $\alpha=0.05$.
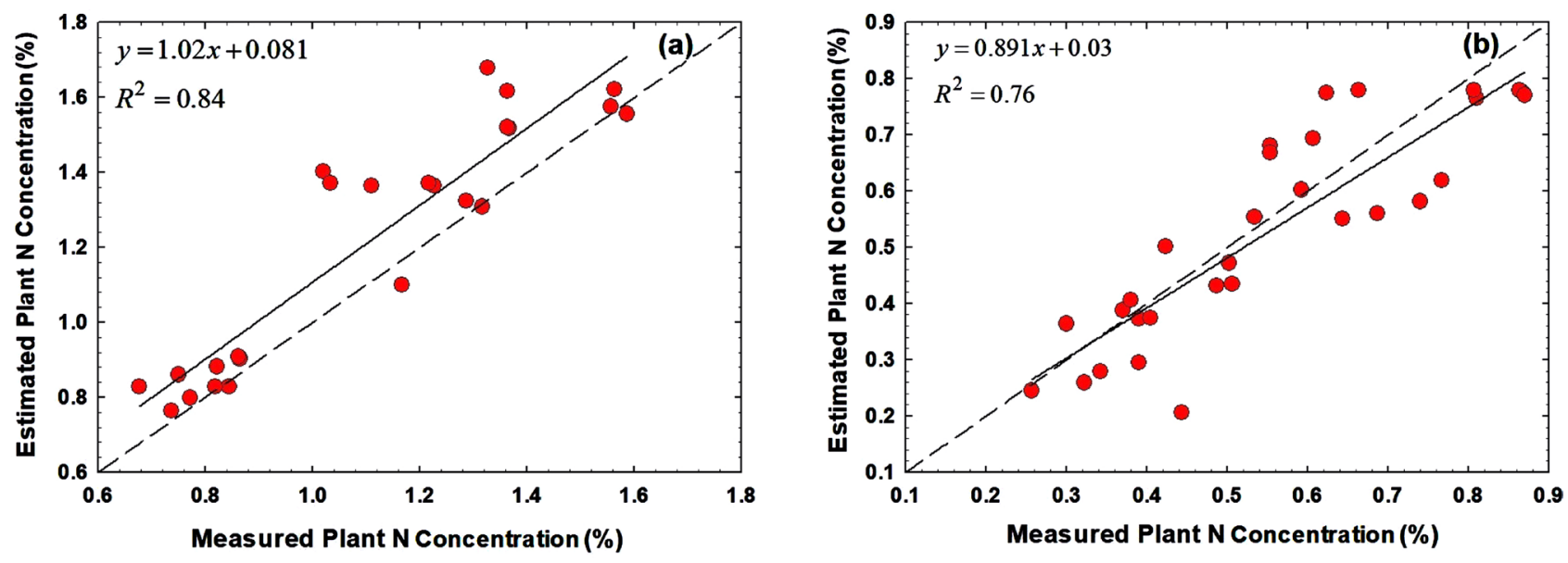

Figure 5. Cross validation of developed algorithms based on (a) $\mathrm{NDVI}_{\text {red edge }}$ at Feekes 5 and (b) $\mathrm{CI}_{\text {green }}$ at Feekes 10 in estimating plant $\mathrm{N}$ concentration of wheat crop in test data sets. 
estimating plant $\mathrm{N}$ concentration. Therefore, growth stage-specific models would be preferred for estimating plant $\mathrm{N}$ concentration. Mid-season plant $\mathrm{N}$ content estimation could significantly improve the opportunity for farmers to intervene with strategic fertilizer management. Ideally, the choice of an index for canopy $\mathrm{N}$ measurement should not depend on the geographical location where measurements are made. The VIs that minimize the soil reflectance, such as red edge based VIs, have the best performance across different locations with different soil type. These kinds of VIs could be used to map N content across farmer fields without calibrations, allowing them to target $\mathrm{N}$ applications. The results mean that adding red edge band to UAV sensors can improve plant $\mathrm{N}$ concentration monitoring and estimation. The main concern about developed models for plant $\mathrm{N}$ concentration estimation is that these models are crop-specific. Each crop has its' own unique spectral signature; thus, the same models cannot be used for various crops. Changes in plant characteristics (such as breeding improvements) may require the development of additional algorithms. Mixed results about the effect of wheat cultivars on spectral reflectance have been reported in literature. Sembiring et al [40] found that wheat varieties did not have significant effect on spectral measurements. On the other hand, Sultana et al [41] documented that spectral reflectance (NDVI) values have varied significantly for a wide range of cultivars treated with the same $\mathrm{N}$ rates.

Remotely sensed VIs have been extensively used to quantify wheat crop N status. The UAV technology appears to provide a good complement to the current remote sensing platforms for $\mathrm{N}$ monitoring in wheat by capturing low-cost, high resolution images. These UAV technologies can bring a unique perspective to $\mathrm{N}$ management in wheat by providing valuable information on wheat $\mathrm{N}$ status. Time, labor and money can be saved using UAV data in crop monitoring.

Results presented in this paper show that high resolution images acquired with UAVs are a useful data source for in-season wheat crop $\mathrm{N}$ concentration estimation. At Feekes 5 growth stage, red edge and green based VIs had higher correlation with plant $\mathrm{N}$ concentration compared to red based VIs because red edge based VIs can reduce the soil background effect on crop reflectance. At Feekes 10 growth stage, all calculated VIs showed high correlation with plant $\mathrm{N}$ concentration, and there were no significant differences between red and red edge based VIs' performance. At this stage, crop canopy has been fully developed, and soil reflectance did not have strong effect on the reflectance of research plots. At Feekes 5, the plant $\mathrm{N}$ concentration estimated based on NDVI $\mathrm{I}_{\text {red }}$ edge showed 1:1 correlation with $\mathrm{N}$ concentration measured in the lab. At Feekes 10 , the estimated and measured $\mathrm{N}$ concentration were highly correlated for all developed models, but the model based on $\mathrm{CI}_{\text {green }}$ was the only model that had a 1:1 correlation between estimated and measured plant $\mathrm{N}$ concentration. The observed high correlation between UAV based VIs with plant $\mathrm{N}$ concentration indicates the applicability of UAV for in-season data collection from agricultural fields. 


\section{Conclusions}

Remotely sensed VIs have been extensively used to quantify wheat crop N status. The UAV technology appears to provide a good complement to the current remote sensing platforms for $\mathrm{N}$ monitoring in wheat by capturing low-cost, high resolution images. These UAV technologies can bring a unique perspective to $\mathrm{N}$ management in wheat by providing valuable information on wheat $\mathrm{N}$ status. Time, labor and money can be saved using UAV data in crop monitoring.

Results presented in this paper show that high resolution images acquired with UAVs are a useful data source for in-season wheat crop $\mathrm{N}$ concentration estimation. At Feekes 5 growth stage, red edge and green based VIs had higher correlation with plant $\mathrm{N}$ concentration compared to red based VIs because red edge based VIs can reduce the soil background effect on crop reflectance. At Feekes 10 growth stage, all calculated VIs showed high correlation with plant $\mathrm{N}$ concentration, and there were no significant differences between red and red edge based VIs' performance. At this stage, crop canopy has been fully developed, and soil reflectance did not have strong effect on the reflectance of research plots. At Feekes 5, the plant $\mathrm{N}$ concentration estimated based on $\mathrm{NDVI}_{\text {red }}$ edge showed 1:1 correlation with $\mathrm{N}$ concentration measured in the lab. At Feekes 10 , the estimated and measured $\mathrm{N}$ concentration were highly correlated for all developed models, but the model based on $\mathrm{CI}_{\text {green }}$ was the only model that had a 1:1 correlation between estimated and measured plant $\mathrm{N}$ concentration. The observed high correlation between UAV based VIs with plant $\mathrm{N}$ concentration indicates the applicability of UAV for in-season data collection from agricultural fields.

\section{Acknowledgements}

This study was supported in part by the Idaho Wheat Commission.

\section{References}

[1] Biswas, D.K. and Ma, B.L. (2016) Effect of Nitrogen Rate and Fertilizer Nitrogen Source on Physiology, Yield, Grain Quality, and Nitrogen Use Efficiency in Corn. Canadian Journal of Plant Science, 96, 392-403. https://doi.org/10.1139/cjps-2015-0186

[2] Jain, N., Ray, S.S., Singh, J.P. and Panigrahy, S. (2007) Use of Hyperspectral Data to Assess the Effects of Different Nitrogen Applications on a Potato Crop. Precision Agriculture, 8, 225-239. https://doi.org/10.1007/s11119-007-9042-0

[3] Walsh, O.S., Shafian, S. and Christiaens, R.J. (2018) Evaluation of Sensor-Based Nitrogen Rates and Sources in Wheat. International Journal of Agronomy, 2018, Article ID: 5670479. https://doi.org/10.1155/2018/5670479

[4] Ramoelo, A., Skidmore, A.K., Schlerf, M., Heitkönig, I.M., Mathieu, R. and Cho, M.A. (2013) Savanna Grass Nitrogen to Phosphorous Ratio Estimation Using Field Spectroscopy and the Potential for Estimation with Imaging Spectroscopy. International Journal of Applied Earth Observation and Geoinformation, 23, 334-343. https://doi.org/10.1016/j.jag.2012.10.009

[5] Li, F., Mistele, B., Hu, Y., Chen, X. and Schmidhalter, U. (2014) Reflectance Estima- 
tion of Canopy Nitrogen Content in Winter Wheat Using Optimised Hyperspectral Spectral Indices and Partial Least Squares Regression. European Journal of Agronomy, 52, 198-209. https://doi.org/10.1016/j.eja.2013.09.006

[6] Reay, D.S., Davidson, E.A., Smith, K.A., Smith, P., Melillo, J.M., Dentener, F. and Crutzen, P.J. (2012) Global Agriculture and Nitrous Oxide Emissions. Nature Climate Change, 2, 410. https://doi.org/10.1038/nclimate1458

[7] Ravishankara, A.R., Daniel, J.S. and Portmann, R.W. (2009) Nitrous Oxide (N2O): The Dominant Ozone-Depleting Substance Emitted in the 21st Century. Science, 326, 123-125.

[8] Bao, Y., Xu, K., Min, J. and Xu, J. (2013) Estimating Wheat Shoot Nitrogen Content at Vegetative Stage from in Situ Hyperspectral Measurements. Crop Science, 53, 2063-2071. https://doi.org/10.2135/cropsci2013.01.0012

[9] Schlemmer, M., Gitelson, A., Schepers, J., Ferguson, R., Peng, Y., Shanahan, J. and Rundquist, D. (2013) Remote Estimation of Nitrogen and Chlorophyll Contents in Maize at Leaf and Canopy Levels. International Journal of Applied Earth Observation and Geoinformation, 25, 47-54. https://doi.org/10.1016/j.jag.2013.04.003

[10] Baret, F., Houles, V. and Guérif, M. (2007) Quantification of Plant Stress Using Remote Sensing Observations and Crop Models: The Case of Nitrogen Management. Journal of Experimental Botany, 58, 869-880.

https://doi.org/10.1093/jxb/erl231

[11] Filella, I., Serrano, L., Serra, J. and Penuelas, J. (1995) Evaluating Wheat Nitrogen Status with Canopy Reflectance Indices and Discriminant Analysis. Crop Science, 35, 1400-1405. https://doi.org/10.2135/cropsci1995.0011183X003500050023x

[12] Sage, R.F., Pearcy, R.W. and Seemann, J.R. (1987) The Nitrogen Use Efficiency of C3 and C4 Plants: III. Leaf Nitrogen Effects on the Activity of Carboxylating Enzymes in Chenopodium album (L.) and Amaranthus retroflexus (L.). Plant Physiology, 85, 355-359. https://doi.org/10.1104/pp.85.2.355

[13] Cammarano, D., Fitzgerald, G., Basso, B., O’Leary, G., Chen, D., Grace, P. and Fiorentino, C. (2011) Use of the Canopy Chlorophyl Content Index (CCCI) for Remote Estimation of Wheat Nitrogen Content in Rainfed Environments. Agronomy Journal, 103, 1597-1603. https://doi.org/10.2134/agronj2011.0124

[14] Xuefeng, L., Qiang, L., Shaolan, H., Shilai, Y., Deyu, H., Zhitao, W., Lie, D., et al. (2016) Estimation of Carbon and Nitrogen Contents in Citrus Canopy by Low-Altitude Remote Sensing. International Journal of Agricultural and Biological Engineering, 9, 149.

[15] Herrmann, I., Karnieli, A., Bonfil, D.J., Cohen, Y. and Alchanatis, V. (2010) SWIR-Based Spectral Indices for Assessing Nitrogen Content in Potato Fields. International Journal of Remote Sensing, 31, 5127-5143.

https://doi.org/10.1080/01431160903283892

[16] Clevers, J.G. and Gitelson, A.A. (2013) Remote Estimation of Crop and Grass Chlorophyll and Nitrogen Content Using Red-Edge Bands on Sentinel-2 and-3. International Journal of Applied Earth Observation and Geoinformation, 23, 344-351. https://doi.org/10.1016/j.jag.2012.10.008

[17] Gitelson, A. and Merzlyak, M.N. (1994) Spectral Reflectance Changes Associated with Autumn Senescence of Aesculus hippocastanum L. and Acer platanoides L. Leaves. Spectral Features and Relation to Chlorophyll Estimation. Journal of Plant Physiology, 143, 286-292. https://doi.org/10.1016/S0176-1617(11)81633-0

[18] Gitelson, A.A., Gritz, Y. and Merzlyak, M.N. (2003) Relationships between Leaf Chlorophyll Content and Spectral Reflectance and Algorithms for Non-Destructive 
Chlorophyll Assessment in Higher Plant Leaves. Journal of Plant Physiology, 160, 271-282. https://doi.org/10.1078/0176-1617-00887

[19] Dash, J. and Curran, P.J. (2004) The MERIS Terrestrial Chlorophyll Index.

[20] Wang, Y., Liao, Q., Yang, G., Feng, H., Yang, X. and Yue, J. (2016) Comparing Broad-Band and Red Edge-Based Spectral Vegetation Indices to Estimate Nitrogen Concentration of Crops Using Casi Data. International Archives of the Photogrammetry, Remote Sensing and Spatial Information Sciences, 137-143. https://doi.org/10.5194/isprsarchives-XLI-B7-137-2016

[21] Maes, W.H., Huete, A.R. and Steppe, K. (2017) Optimizing the Processing of UAV-Based Thermal Imagery. Remote Sensing, 9, 476. https://doi.org/10.3390/rs9050476

[22] Pádua, L., Vanko, J., Hruška, J., Adão, T., Sousa, J.J., Peres, E. and Morais, R. (2017) UAS, Sensors, and Data Processing in Agroforestry: A Review towards Practical Applications. International Journal of Remote Sensing, 38, 2349-2391. https://doi.org/10.1080/01431161.2017.1297548

[23] Simelli, I. and Tsagaris, A. (2015) The Use of Unmanned Aerial Systems (UAS) in Agriculture. HAICTA, Kavala, 17-20 September 2015, 730-736.

[24] Lu, J., Miao, Y., Huang, Y., Shi, W., Hu, X., Wang, X. and Wan, J. (2015) Evaluating an Unmanned Aerial Vehicle-Based Remote Sensing System for Estimation of Rice Nitrogen Status. 4th International Conference on Agro-Geoinformatics, Istanbul, 20-24 July 2015, 198-203.

[25] Caturegli, L., Corniglia, M., Gaetani, M., Grossi, N., Magni, S., Migliazzi, M., Raffaelli, M., et al. (2016) Unmanned Aerial Vehicle to Estimate Nitrogen Status of Turfgrasses. PLOS ONE, 11, e0158268. https://doi.org/10.1371/journal.pone.0158268

[26] Hunt, E.R. and Rondon, S.I. (2017) Detection of Potato Beetle Damage Using Remote Sensing from Small Unmanned Aircraft Systems. Journal of Applied Remote Sensing, 11, Article ID: 026013. https://doi.org/10.1117/1.JRS.11.026013

[27] Mission Planner Home. http://ardupilot.org/planner

[28] Shi, Y., Thomasson, J.A., Murray, S.C., Pugh, N.A., Rooney, W.L., Shafian, S., Rana, A., et al. (2016) Unmanned Aerial Vehicles for High-Throughput Phenotyping and Agronomic Research. PLOS ONE, 11, e0159781.

https://doi.org/10.1371/journal.pone.0159781

[29] Official Methods of Analysis of AOAC International.

http://www.aoac.org/aoac_prod_imis/aoac/publications/official_methods_of_analys is/aoac_member/pubs/oma/aoac_official_methods_of_analysis.aspx?hkey=5142c47 8-ab50-4856-8939-a7a491756f48

[30] Rouse Jr., J., Haas, R.H., Schell, J.A. and Deering, D.W. (1974) Monitoring Vegetation Systems in the Great Plains with ERTS.

[31] Huete, A., Didan, K., Miura, T., Rodriguez, E.P., Gao, X. and Ferreira, L.G. (2002) Overview of the Radiometric and Biophysical Performance of the MODIS Vegetation Indices. Remote Sensing of Environment, 83, 195-213. https://doi.org/10.1016/S0034-4257(02)00096-2

[32] Gitelson, A.A., Vina, A., Ciganda, V., Rundquist, D.C. and Arkebauer, T.J. (2005) Remote Estimation of Canopy Chlorophyll Content in Crops. Geophysical Research Letters, 32, L08403. https://doi.org/10.1029/2005GL022688

[33] Nicolas, T., Philippe, V. and Huang, W.J. (2010) New Index for Crop Canopy Fresh Biomass Estimation. Spectroscopy and Spectral Analysis, 30, 512-517. 
[34] Plénet, D. and Lemaire, G. (1999) Relationships between Dynamics of Nitrogen Uptake and Dry Matter Accumulation in Maize Crops. Determination of Critical N Concentration. Plant and Soil, 216, 65-82. https://doi.org/10.1023/A:1004783431055

[35] Muñoz-Huerta, R.F., Guevara-Gonzalez, R.G., Contreras-Medina, L.M., TorresPacheco, I., Prado-Olivarez, J. and Ocampo-Velazquez, R.V. (2013) A Review of Methods for Sensing the Nitrogen Status in Plants: Advantages, Disadvantages and Recent Advances. Sensors, 13, 10823-10843. https://doi.org/10.3390/s130810823

[36] Lü, X.T., Dijkstra, F.A., Kong, D.L., Wang, Z.W. and Han, X.G. (2014) Plant Nitrogen Uptake Drives Responses of Productivity to Nitrogen and Water Addition in a Grassland. Scientific Reports, 4, Article No. 4817. https://doi.org/10.1038/srep04817

[37] Viña, A., Gitelson, A.A., Nguy-Robertson, A.L. and Peng, Y. (2011) Comparison of Different Vegetation Indices for the Remote Assessment of Green Leaf Area Index of Crops. Remote Sensing of Environment, 115, 3468-3478. https://doi.org/10.1016/j.rse.2011.08.010

[38] Li, F., Miao, Y., Hennig, S.D., Gnyp, M.L., Chen, X., Jia, L. and Bareth, G. (2010) Evaluating Hyperspectral Vegetation Indices for Estimating Nitrogen Concentration of Winter Wheat at Different Growth Stages. Precision Agriculture, 11, 335-357. https://doi.org/10.1007/s11119-010-9165-6

[39] Todd, S.W. and Hoffer, R.M. (1998) Responses of Spectral Indices to Variations in Vegetation Cover and Soil Background. Photogrammetric Engineering and Remote Sensing, 64, 915-922.

[40] Sembiring, H., Raun, W.R., Johnson, G.V., Stone, M.L., Solie, J.B. and Phillips, S.B. (1998) Detection of Nitrogen and Phosphorus Nutrient Status in Winter Wheat Using Spectral Radiance. Journal of Plant Nutrition, 21, 1207-1233. https://doi.org/10.1080/01904169809365478

[41] Sultana, S.R., Ali, A., Ahmad, A., Mubeen, M., Zia-Ul-Haq, M., Ahmad, S., Jaafar, H.Z., et al. (2014) Normalized Difference Vegetation Index as a Tool for Wheat Yield Estimation: A Case Study from Faisalabad, Pakistan. The Scientific World Journal, 2014, Article ID: 725326. https://doi.org/10.1155/2014/725326 